\title{
A CROSS-SECTIONAL STUDY ON THE PREVALENCE AND RISK FACTORS OF LYMPHEDEMA IN CARCINOMA BREAST
}

VISHNU GOPAL*, ABHINABHA ACHARYA, VASUDHA NARAYANASWAMY, SANTANU PAL

Department of Radiotherapy, Institute of Post Graduate Medical Education and Research and Sekh Sukhlal Karnani Memorial Hospital, Kolkata, West Bengal, India. Email: vishnugopal1987@gmail.com

Received: 10 November 2016, Revised and Accepted: 27 March 2017

\section{ABSTRACT}

Objectives: Lymphedema of the arm is a devastating complication of breast carcinoma treatment. There is a lack of research on the risk factors and methods of preventing upper limb lymphedema after breast carcinoma treatment. The aims of the study are to identify the prevalence and risk factors for upper limb lymphedema in patients attending a tertiary cancer care center in India.

Methods: 199 patients who attended the outpatient department of radiotherapy of IPGMER and SSKM, after undergoing surgical treatment for breast cancer between November 2014 to May 2016 were examined for the presence of lymphedema and its risk factors were analyzed. Lymphedema was defined as being present when there is an increase of $>5 \%$ sum difference in the arm circumferences measured at different levels of both the upper limbs.

Results: Of the 199 patients analyzed, 85 (42.7\%) patients were found to have lymphedema. The prevalence of lymphedema was $25 \%$ in those who underwent surgery alone and $54 \%$ in those who underwent chest wall radiotherapy also. Locally advanced stage of the disease, body mass index $>25 \mathrm{~kg} / \mathrm{m}^{2}$, number of lymph nodes removed during surgery, and adjuvant radiotherapy were found to be significant risk factors for the development of lymphedema.

Conclusion: Based on the results of this study, we recommend weight reduction and more judicious axillary lymph node dissection and use of postoperative radiotherapy as methods to prevent breast cancer-associated lymphedema in the tertiary cancer care centers in India.

Keywords: Breast cancer, Radiotherapy, Lymphedema.

(C) 2017 The Authors. Published by Innovare Academic Sciences Pvt Ltd. This is an open access article under the CC BY license (http://creativecommons. org/licenses/by/4. 0/) DOI: http://dx.doi.org/10.22159/ajpcr.2017.v10i6.16118

\section{INTRODUCTION}

Cancer is a kind of disease in which a group of cells undergoes uncontrollable cell growth, invasion, or metastasis. Worldwide, breast cancer is the second most common type cancer after lung cancer. Breast cancer is the most frequently diagnosed cancer in urban woman. Due to advances in early detection and application of multimodality treatment, breast cancer mortality rates have declined in recent years. Although an increasing number of patients are surviving long term after multimodality treatment, some women develop lymphedema of the ipsilateral arm after treatment. Those patients with arm edema secondary to breast cancer treatment experience a substantial degree of functional impairment, psychological morbidity, and diminished quality of life [1-5].

Most studies on lymphedema concentrate on its management emphasizing the use of compression garments, bandaging, pumps, massage, and exercise. Many researchers have analyzed the clinical and pathologic risk factors for lymphedema. Even though locoregional therapy for breast in the form of surgery and radiotherapy are wellestablished risk factors of lymphedema of the arm, majority of the other risk factors still remain unclear [6-12].

Arm edema in breast cancer patients occurs due to interruption of axillary lymphatic system, mainly due to surgery and radiotherapy, which results in the accumulation of fluid in subcutaneous tissues in the arm with decreased distensibility of tissues around the joints and increased weight of the arm. Other reported predisposing risk factors include age, infection, obesity, other preexisting comorbid conditions (such as cardiovascular conditions), and the surgical technique used, but all the reports are conflicting [13].
The overall treatment approach toward breast cancer has changed in the recent past and the present trend is toward less radical surgical procedures and more conformal radiation therapy. Still the risk of lymphedema persists for every patient who had undergone any form of locoregional therapy to the breast and there may also be other predisposing factors in lymphedema development which are not yet present in the available guidelines.

\section{METHODS}

199 patients attending radiotherapy outpatient department of IPGMER and SSKM, Kolkata during November 2014 - May 2016 were included in the study. The following criteria were used in selecting the patients.

Inclusion criteria

- Female breast cancer patients.

- Those with early or locally advanced disease.

- Those who had undergone surgery for breast cancer.

- A minimum follow-up of 6 months after surgery.

Exclusion criteria

- Patients with metastatic disease

- Who had not undergone surgery or those who underwent a less radical surgery than modified radical mastectomy (MRM),

- Those with follow-up of $<6$ months,

- Male breast cancer patients.

This study included 217 subjects, after informing them about the purpose of the study and taking prior consent from them. Patient's details including age, body surface area, menopausal status, follow-up period, stage of the disease, and treatment received were recorded in a 
pro forma. Details of chemotherapy (regimens and number of cycles) and radiotherapy (technique, dose, and extent of radiation) were also collected.

The circumference of both the upper limbs was measured in 6 placesarmpit, halfway down the upper arm, elbow, halfway down the forearm, wrist, and hand with the thumb. In each area, a percent difference was calculated standardizing the absolute differences between 2 circumferences by the largest circumference. The total sum of the percent differences between the two upper limbs was used to define the presence of lymphedema. All patients having a sum of percent differences of $>5 \%$ were classified as having lymphedema [14]. All measurements were taken by the same investigator who was trained and practiced in this technique. Since there was a departmental protocol of measuring mid-arm and mid-forearm measurements of all breast cancer patients on follow-up, all measurements were recorded independently taken at the previous visits to reduce bias.

All patients attending our outpatient department during the study period who had finished 6 months of follow-up after the date of surgery for breast cancer were enrolled in the study. Patients who had lymphedema during any of their follow-up visits were not examined again and those who did not have lymphedema at the time of initial examination after enrollment were also examined during their follow-up visits for the development of lymphedema till the end of study period.

Statistical analysis was done using Statistical Package for the Social Sciences version 15 and the statistical significance was calculated using the Chi-square test.

\section{RESULTS}

217 patients were examined during the study period. However, 18 of them were excluded from the final analysis due to inadequate documentation. Tracing of data of the final 199 patients were nearly total.

The median age was 51 years and the median follow-up period was 33 months. $43 \%$ of the patients had locally advanced disease and $44.2 \%$ patients had a body mass index (BMI) of $>25 \mathrm{~kg} / \mathrm{m}^{2}$. All but 2 patients underwent MRM and the other 2 patients underwent radical mastectomy. The average number of nodes removed during surgery was 13 (ranging from 4 to 33). 139 patients (70\%) underwent radiotherapy using two-dimensional (2D) techniques for a total dose of 50 Gy in 2 Gy per fraction and 162 (81\%) patients received chemotherapy of different regimens.

The prevalence of lymphedema was observed to be $42.7 \%$ among all the patients after analysis. The prevalence of lymphedema was $25 \%$ in those who were treated with surgery alone and 54\% in those who were treated with both surgery and radiotherapy. Lymphedema was noticed in $58 \%$ with locally advanced breast cancer, $58 \%$ with BMI $>25 \mathrm{~kg} / \mathrm{m}^{2}$, and in $60 \%$ who had got $>10$ lymph nodes dissected during surgery.

After the final analysis stage of the disease, BMI, addition of radiotherapy to surgery, and number of lymph nodes removed during surgery came out as statistically significant factors in univariate analysis (Tables 1-5).

\section{DISCUSSION}

Worldwide, breast cancer comprises $22.9 \%$ of all cancers in women. It is 100 times and more common in women than in men although men tend to have poorer outcomes due to delays in diagnosis. The incidence of breast cancer is rising in every country of the world, especially in developing countries such as India [15]. Breast cancerrelated secondary lymphedema presents a significant problem for the affected patients. Patients and patient's family expect the patient to lead a normal life after going through all the trauma of cancer treatment. Apart from local recurrence and distant recurrence, gross lymphedema
Table 1: Stage

\begin{tabular}{lll}
\hline Stage & $\begin{array}{l}\text { Those without } \\
\text { lymphedema (\%) }\end{array}$ & $\begin{array}{l}\text { Those with } \\
\text { lymphedema (\%) }\end{array}$ \\
\hline $\begin{array}{l}\text { Early breast cancer } \\
\text { Locally advanced breast } \\
\text { cancer }\end{array}$ & $\begin{array}{l}78 / 113(69) \\
\text { (6) }\end{array}$ & $\begin{array}{l}35 / 113(31) \\
50 / 86(58)\end{array}$ \\
\hline
\end{tabular}

The Chi-square statistic is 14.7286 and the $p<0.05$ which is statistically significant

Table 2: BMI

\begin{tabular}{lll}
\hline BMI & $\begin{array}{l}\text { Those without } \\
\text { lymphedema (\%) }\end{array}$ & $\begin{array}{l}\text { Those with } \\
\text { lymphedema (\%) }\end{array}$ \\
\hline$<25 \mathrm{~kg} / \mathrm{m}^{2}$ & $73 / 111(66)$ & $38 / 111(34)$ \\
$>25 \mathrm{~kg} / \mathrm{m}^{2}$ & $41 / 88(42)$ & $47 / 88(58)$ \\
& 114 & 85 \\
\hline
\end{tabular}

The Chi-square statistic is 7.3756 an the $p<0.05$ which is statistically significant, BMI: Body mass index

Table 3: Radiotheraphy

\begin{tabular}{lll}
\hline Radiotherapy & $\begin{array}{l}\text { Those without } \\
\text { lymphedema (\%) }\end{array}$ & $\begin{array}{l}\text { Those with } \\
\text { lymphedema (\%) }\end{array}$ \\
\hline No & $45 / 60(75)$ & $15 / 60(25)$ \\
Yes & $64 / 139(36)$ & $75 / 139(54)$ \\
& 114 & 85 \\
\hline
\end{tabular}

The Chi-square statistic is 14.1857 and the $p<0.05$ which is statistically significant

Table 4: Number of lymph nodes removed

\begin{tabular}{lll}
\hline $\begin{array}{l}\text { Number of lymph } \\
\text { nodes removed }\end{array}$ & $\begin{array}{l}\text { Those without } \\
\text { lymphedema (\%) }\end{array}$ & $\begin{array}{l}\text { Those with } \\
\text { lymphedema (\%) }\end{array}$ \\
\hline$<10$ & $47 / 58(81)$ & $11 / 58(19)$ \\
$>10$ & $57 / 141(40)$ & $84 / 141(60)$ \\
& 114 & 85 \\
\hline
\end{tabular}

The Chi-square statistic is 27.1636 and the the $p<0.05$ which is statistically significant

Table 5: Chemotherapy

\begin{tabular}{lll}
\hline Chemotherapy & $\begin{array}{l}\text { Those without } \\
\text { lymphedema (\%) }\end{array}$ & $\begin{array}{l}\text { Those with } \\
\text { lymphedema (\%) }\end{array}$ \\
\hline No & $20 / 37(54)$ & $17 / 37(46)$ \\
Yes & $94 / 162(58)$ & $68 / 162(42)$ \\
& 114 & 85 \\
\hline
\end{tabular}

The Chi-square statistic is 0.1941 and the $p>0.05$ which is not statistically significant

of the arm is one of the most dreadful complications which can arise after breast cancer treatment which will result in significant reduction in the quality of the life of the patients. Furthermore, there has been virtually no systematic research in the area of preventive strategies for arm lymphedema associated with breast cancer treatment. Randomized control trials and well-conducted retrospective studies are needed to clearly evaluate the preventive measures and to assess the risk factors for the development of lymphedema.

Lymphedema can be defined as a pathologic state characterized by chronic inflammatory fibrosis and hypertrophy of the hypodermal and dermal connective tissue due to lymphatic blockage mainly due to surgery and radiotherapy [16]. Across a number of studies, lymphedema has been reported to occur approximately in 41\% (range of $21-51 \%$ ) of patients who undergo axillary radiotherapy in addition 
to surgery as opposed to approximately 17\% (range 6-39\%) of patients treated with surgery and no axillary radiotherapy [17]. There is wide variation in prevalence and it is due to lack of consensus regarding the clinical criteria, method of assessment, and timing of assessment for lymphedema.

During the era of radical mastectomy, the reported incidence of lymphedema varied from $49-63 \%$. Subsequently, during the MRM era, the lymphedema prevalence has shown a decreasing trend and the reported rates of lymphedema following MRM varies from $24 \%$ to $28 \%$. Postoperative radiotherapy can aggravate lymphedema by inducing fibrosis, scar formation, and radiodermatitis.

Various methods have been described in literature for assessment of lymphedema including volumetric methods (water displacement methods), serial circumferential measurement technique, magnetic resonance imaging, bioelectrical impedance, and tonometry $[18,19]$. Serial circumferential measurements were used in this study because of its simplicity and reproducibility.

A complete axillary lymph node dissection was considered to be a critical component of surgical cure of breast cancer patients until recently. This changed when studies such as NSABP-04 [20] came out in which the patients were randomized to radical mastectomy, total mastectomy with radiotherapy to regional lymphatics, or total mastectomy with observation of axillary lymphatics and delayed axillary lymph node dissection showed no benefit over axillary surgery. Recently, lymphatic mapping and sentinel lymph node biopsy is replacing axillary lymph node dissection as the staging procedure in clinically node-negative woman.

Even though this is the development regarding management of axilla in the developed countries, we are still devoid of such facilities such as sentinel lymph node biopsy in most of our government centers. Hence, it is appropriate to think about the other preventable risk factors which can be applied in daily life practice. Apart from surgery and radiotherapy, many other risk factors are described in literature such as age, presence of comorbid conditions, infection, obesity, stage of disease, and systemic therapy. In this study, we tried to assess some of those risk factors.

Apart from the conventional 2D radiotherapy treatment, imagebased three-dimensional (3D) techniques such as 3D conformal radiation therapy, intensity-modulated radiation therapy, and imageguided radiation therapy have evolved. These technologies help in reducing doses to normal tissues including the lymphatic tissues. This should lead to reduction of fibrosis and other changes, which contribute to lymphedema. This should in turn reduce the incidence of lymphadenopathy in such patients. However, till date, there is no published data validating this. Furthermore, the normal conventional fields irradiate level I and II axillary lymph nodes. Hence, the need for extensive lymph node dissection has also been questioned with the concept of axillary nodal sampling in clinically node-negative patients.

The limitations of the study are its study design (longer follow-up needed for patients with short follow-up), small number of patients, and a lack of standardized method of diagnosing lymphedema. One major possible confounding factor is the role of chemotherapy and the use of anthracyclines in the development of lymphedema which was shown as a risk factor in some previous studies. Furthermore, patients who underwent simple mastectomy and breast conserving surgery were excluded which could be a confounding factor and there could be patients who will not turn up for regular follow-up after the initial treatment, whose numbers may be missing from this study, which could be also a confounding factor.

Despite limited numbers and many limitations, this study clearly proves that locally advanced stage, obesity, higher number of lymph nodes resected, and addition of radiotherapy increases the chances for lymphedema.

\section{CONCLUSION}

In the postradical mastectomy era, the incidence rates of lymphedema have shown a decreasing trend. Furthermore, in the current scenario, the radiation therapy is also gradually changing from $2 \mathrm{D}$ radiotherapy to $3 \mathrm{D}$ radiotherapy. Does this change from $2 \mathrm{D}$ to $3 \mathrm{D}$ have a say on the prevalence of lymphedema in patients who had undergone surgery? The answer of this question will remain unanswered till further studies are conducted. Based on our study, we recommend weight reduction and judicial use of radiotherapy whenever feasible in the tertiary cancer care centers of our country. Furthermore, extensive lymph node dissection is questioned in node-negative patients with the concept of axillary lymph node sampling coming up. Furthermore, the involvement of a physical medicine specialist in the holistic management of every breast carcinoma patient soon after diagnosis is very important.

\section{REFERENCES}

1. Maunsell E, Brisson J, Deschênes L. Arm problems and psychological distress after surgery for breast cancer. Can J Surg 1993;36(4):315-20.

2. Carter BJ. Women's experiences of lymphedema. Oncol Nurs Forum 1997;24(5):875-82.

3. Passik S, Newman M, Brennan M, Holland J. Psychiatric consultation for women undergoing rehabilitation for upper-extremity lymphedema following breast cancer treatment. J Pain Symptom Manage 1993;8(4):226-33

4. Velanovich V, Szymanski W. Quality of life of breast cancer patients with lymphedema. Am J Surg 1999;177(3):184-7.

5. Kanagathara N, Kavitha K. Evaluation of HER-2/neu over expression in breast cancer. Int J Pharm Pharm Sci 2014;6(2):898-900.

6. Suneson BL, Lindholm C, Hamrin E. Clinical incidence of lymphoedema in breast cancer patients in Jönköping County, Sweden. Eur J Cancer Care 1996;5(1):7-12.

7. Senofsky GM, Moffat FL Jr, Davis K, Masri MM, Clark KC, Robinson DS, et al. Total axillary lymphadenectomy in the management of breast cancer. Arch Surg 1991;126(11):1336-41.

8. Segerström K, Bjerle P, Graffman S, Nyström A. Factors that influence the incidence of brachial oedema after treatment of breast cancer. Scand J Plast Reconstr Surg Hand Surg 1992;26(2):223-7.

9. Schünemann $\mathrm{H}$, Willich N. Lymphedema after breast carcinoma. A study of 5868 cases. Dtsch Med Wochenschr 1997;122(17):536-41.

10. Meek AG. Breast radiotherapy and lymphedema. Cancer 1998;83 12 Suppl:2788-97.

11. Rockson SG. Precipitating factors in lymphedema: Myths and realities. Cancer 1998;83 12 Suppl:2814-6.

12. Schünemann $\mathrm{H}$, Willich $\mathrm{N}$. Lymphoedema of the arm after primary treatment of breast cancer. Anticancer Res 1998;18(3C):2235-6.

13. Shaw C, Mortimer P, Judd PA. Randomized controlled trial comparing a low-fat diet with a weight-reduction diet in breast cancer-related lymphedema. Cancer 2007;109(10):1949-56.

14. Herd-Smith A, Russo A, Muraca MG, Del Turco MR, Cardona G. Prognostic factors for lymphedema after primary treatment of breast carcinoma. Cancer 2001;92(7):1783-7.

15. Lakshmi R, Vijayalakshmi S, Raju A, Joy TM. Assessment of various risk factors of breast cancer. Asian J Pharm Pharm Sci 2013;5(4):675-8.

16. Deo SV, Ray S, Rath GK, Shukla NK, Kar M, Asthana S, et al. Prevalence and risk factors for development of lymphedema following breast cancer treatment. Indian J Cancer 2004;41(10):8-12.

17. Erickson VS, Pearson ML, Ganz PA, Adams J, Kahn KL. Arm edema in breast cancer patients. J Natl Cancer Inst 2001;93(2):96-111.

18. Pain SJ, Purushotham AD. Lymphoedema following surgery for breast cancer. Br J Surg 2000;87(9):1128-41.

19. Margaret LF. Lymphedema. In: Berger AM, Portenoy RK, Weissman DE, editors. Principles and Practice of Supportive Oncology. New York: Lippincott-Raven; 1998. p. 275-89.

20. Fisher B, Montague E, Redmond C, Deutsch M, Brown GR, Zauber A, et al. Findings from NSABP Protocol No. B-04-comparison of radical mastectomy with alternative treatments for primary breast cancer. Cancer 1980;46(1):1-13. 